\title{
Radiation Protection Congress
}

Report on the International Congress on Protection against Accelerator and Space Radiation held at CERN on 26-30 April

In comparison with the problems posed by the installation of nuclear power stations or the testing of nuclear weapons, the protection of people in and around high energy physics laboratories appears relatively straight forward, and there are few of us who are worried about the radiation risks associated with cosmic rays. This is no doubt due, on the one hand, to the adequacy of radiation protection measures in and around accelerator laboratories and, on the other, to the fact that we live under a protective screen equivalent to about $10 \mathrm{~m}$ of water which has ensured the survival of the human race even under the worst solar flare conditions.

The trend in high energy physics is towards higher energies and intensities; the trend in travel is towards higher altitudes with the risk of exposure to greater fluxes of natural high energy radiation. It was logical therefore that the groups thinking about safety and protection in the two fields should come together. Organized by CERN, the Société Française de Radioprotection and the Fachverband für Strahlenschutz of the Federal Republic of Germany and Switzerland (represented by J. Baarli, $M$. Avargues and $G$. Poretti), an International Congress was held from 26 to 30 April at CERN on 'Protection against Accelerator and Space Radiation'. More than 200 people participated from some 20 countries, including all those with a significant space or high energy physics programme.

The presence of biologists ensured that one was always aware of the fact that the subject under discussion concerned primarily human beings, although several aspects could be discerned - the academic (concerned with the fundamental characteristics of energy transfer and biological damage); the instrumental (concerned with measuring the desired quantities) ; the organizational (concerned with translating the known information into practical design data and providing the necessary protection service in an economic way).

Atomic energy developments have stimulated an enormous amount of work at low energies on the somatic and genetic effects of radiation and the recommendations of the International Committee for Radiological Protection are virtually universally accepted. Moreover they are explicit and relatively straightforward in interpretation. Extrapolation to high energies, however, is open to various interpretations and there is, as yet, almost no direct biological evidence.

One of the problems in establishing new norms is to get agreement on the quantities that should be measured. The rad is still a perfectly respectable unit which describes the energy deposited macroscopically in a volume of one gram of matter. The LET (linear energy transfer) may mean something different to the physicist and the biologist. The physicist tends to think in terms of the microscopic energy loss from the incident particle, the biologist of the local energy deposition in the tissue.

Confusion also arises in the difference between RBE (relative biological effectiveness) and QF (quality factor), the former is a quantity determined from radiobiological experiments and depends on exposure and biological conditions, while the latter is used exclusively for estimating dose-equivalent for radiation protection purposes. Dose-equivalent, which is $\mathrm{rad} \times \mathrm{QF}$, has units of rem (Röntgen equivalent man) and is the unit in which radiation effect on you and me is measured. Ambiguities in the interpretation of the units stimulated a special meeting prior to the Congress sponsored by the International Atomic Energy Agency and the World Health Organi- zation both of whom have an interest in putting a little more order into the situation.

From the point of view of practical politics however, even if there are still no perfect mathematical models linking dose and damage, there is good evidence for basing protection systems on the assumption that the flux and the LET are the important quantities which take adequately into account the number of the incident particles and the density of energy deposition. At the dose rates likely to be encountered, damage is proportional to total dose.

To put a few numbers down: the ICRP recommends that exposures to the population should not exceed 5 rem in 30 years equal to a constant rate of 170 mrem per year (19 mrem per hour). The design of the new large accelerator at CERN specifies that, on the basis of present evidence, with a $1000 \mathrm{GeV}$ beam and a loss in the ring of less than $5 \%$ with $6 \times 10^{6}$ pulses per year, the surface dose should be only $1 / 5$ of this figure. (The ring is actually $3 \mathrm{~m}$ deeper than is necessary giving an additional factor of 80 .) The protection at the Batavia accelerator, $\mathrm{NAL}$, is designed so that even with a catastrophic beam loss the maximum possible dose on a public road would not exceed $85 \mathrm{mrem}$. Papers from the USSR (quoting also data from other sources) gave the equivalent dose in rems from incident protons or neutrons in the range 0.4 to $2 \mathrm{GeV}$ as 6 to 20 rem for an incident radiation of $10^{8}$ particles per $\mathrm{cm}^{2}$. Zond-5 on its moon trip recorded a total proton incidence of $3.2 \times 10^{6}$ per $\mathrm{cm}^{2}$ giving a calculated dose of less than 1 rem.

In a violent solar flare Concorde could encounter doses of up to $1 \mathrm{rem}$ per hour so that on-board warning is needed and the aircraft will need to dive to maintain the dose-rate below $100 \mathrm{mrem} / \mathrm{h}$. (It is expected that the frequency of the need for evasive 


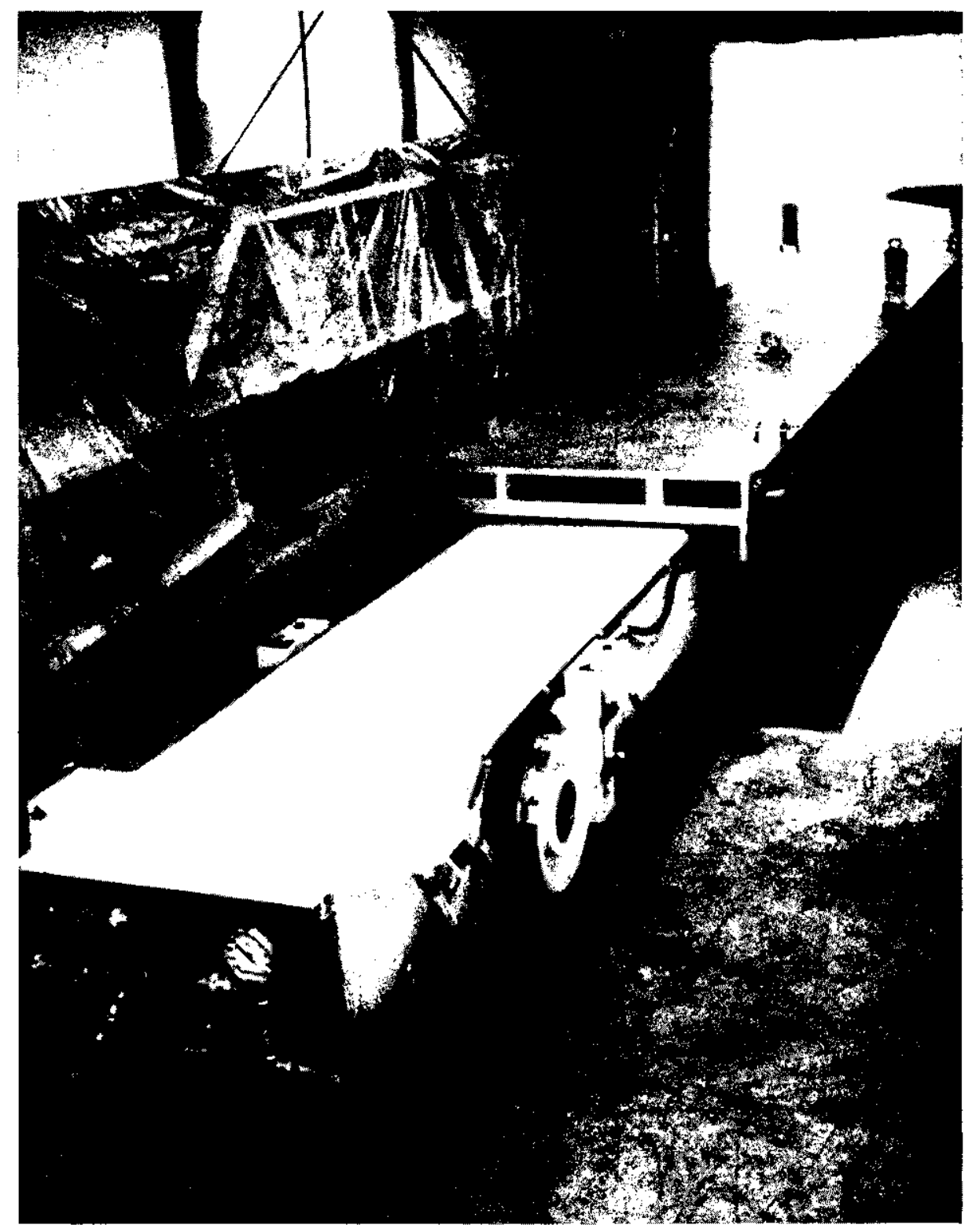

action about equals that of an engine failure - if that's any comfort.)

With the growth of the subject of radiation protection, considerable effort has been put into the development of instrumentation which can distinguish the LET as well as the rad, particularly for higher energy radiation. There is an everyday need for field instruments and personal dosimeters which give results which are unequivocal and 'good enough'. Set against these last criteria, the speaker from NAL hailed the lithium fluoride in polythene detector, M3, as the greatest breakthrough in health physics instrumentation in ten years.

During the Congress, a number of approaches to the detailed calculation of shielding values were presented. The problem at high energies is complicated by the production of secondaries of high penetration, spallation effects and the production of stars and showers, as well as by the sheer
The mobile target positioning trolley at NAL. The target, surrounded by steel shielding, can be placed in the beam line with high precision. The steel limits the activation of the soil in the surrounding area.

(Photo NAL)

also laboratory managements and experimenters. There was also a universal wish that the radiation protection service be called in when new facilities are designed rather than after they have been built and proved to be inadequately shielded.

There was still, however, room for different philosophies of approach. At $\mathrm{NAL}$, the tight budget and schedule has meant that capital installations have been reduced to a minimum. Shielding has been calculated on the basis of $0.1 \%$ beam loss but more could be added if it proved inadequate. Target installations are designed to be removable for easy disposal. Remote handling techniques within the ring and service areas are reduced to a minimum and no hot labs are installed. The beam dumps are of aluminium surrounded by steel in a water tank and during operation rely on the heat capacity of the system. The water is only sent through the heat exchangers when the accelerator shuts down, to avoid the problems associated with short-lived activity in water circuits.

The main ring at NAL, like the ISR at CERN, is provided with a multiplex coupled system of monitors since automation has to be used when the areas involved become so large. Such systems have an additional value in giving information to the machine operators on beam loss. But they do not dispense with detailed surveys.

A warning of things to come was the heart-rending story of the fight to save the local children from self destruction (aided and abetted by the local cathedral authorities) in the precints of the Liverpool cyclotron and then the problem posed by the need to dispose of this gallant machine now condemned to oblivion. Is there no one with a requirement for a 300 ton steel muon shield who is not allergic to an odd residual gamma or two? 